Article

\title{
Thirty-two Years of Sahelian Zone Growing Season Non-Stationary NDVI3g Patterns and Trends
}

\author{
Assaf Anyamba *, Jennifer L. Small, Compton J. Tucker and Edwin W. Pak \\ GIMMS Group, Biospheric Sciences Laboratory, Code 618.0, NASA Goddard Space Flight Center, \\ Greenbelt, MD 20771, USA; E-Mails: Jennifer.1.small@nasa.gov (J.L.S.); \\ Compton.j.tucker@nasa.gov (C.J.T.); edwin.w.pak@nasa.gov (E.W.P.) \\ * Author to whom correspondence should be addressed; E-Mail: assaf.anyamba@nasa.gov; \\ Tel.: +1-301-614-6601; Fax: +1-301-614-6699.
}

Received: 16 January 2014; in revised form: 22 March 2014 / Accepted: 26 March 2014 / Published: 4 April 2014

Abstract: We update the Global Inventory Modeling and Mapping Studies (GIMMS) analysis of Sahelian vegetation dynamics and trends using the normalized difference vegetation index (NDVI; version 3g) 1981 to 2012 data set. We compare the annual NDIV3g and July to October growing season averages with the three rainfall data sets: the Africa Rainfall Climatology from 1983 to 2012, the Variability Analyses of Surface Climate Observations Version-1.1 from 1951 to 2000, and the Nicholson ground-station precipitation rainfall data from 1981 to 1994 . We use the Nicholson ground-station annual precipitation data to determine the reliability of the two continental precipitation data sets for specific locations and specific times, extrapolate these confirmed relationships over the Sahelian Zone from 1983 to 2012 with the Africa Rainfall Climatology, and then place these zonal findings within the 1951 to 2000 record of the Variability Analyses of Surface Climate Observations Version-1.1 precipitation data set. We confirm the extreme nature of the 1984-1985 Sahelian drought, a signature event that marked the minima during the 1980s desiccation period followed within ten years by near-maxima rainfall event in 1994 and positive departures is NDVI, marking beginning of predominantly wetter conditions that have persisted to 2012. We also show the NDVI3g data capture "effective" rainfall, the rainfall that is utilized by plants to grow, as compared to rainfall that evaporates or is runoff. Using our effective rainfall concept, we estimate average effective rainfall for the entire Sahelian Zone for the 1984 extreme drought was $223 \mathrm{~mm} / \mathrm{yr}$ as compared to $406 \mathrm{~mm} / \mathrm{yr}$ in during the 1994 wet period. We conclude that NDVI3g data can used as a 
proxy for analyzing and interpreting decadal-scale land surface variability and trends over semi arid-lands.

Keywords: Sahel; NDVI; rainfall; climate record; growing season; standardized anomalies; extremes; trend patterns

\section{Introduction}

The Sahel Zone is an arid and semi-arid area on the south side of the Sahara, stretching more than $5000 \mathrm{~km}$ across Africa, from the Atlantic Ocean to the Red Sea, with an unusual precipitation gradient of $1 \mathrm{~mm} / \mathrm{yr} / \mathrm{km}$ in a north to south direction. Many workers [1-7] describe the Sahel as the long-term 200 to $400 \mathrm{~mm} / \mathrm{yr}$ mean annual precipitation zone, with a 100 to $200 \mathrm{~mm} / \mathrm{yr}$ transition zone with the Sahara Desert to the north, and a 400-600 mm/yr transition zone with the Sudanian Zone to the south. We will use the 200 to $600 \mathrm{~mm} / \mathrm{yr}$ long-term precipitation isolines as our region of interest in this paper. The Sahel and its transition zones occupy an area of $\sim 2.5$ million $\mathrm{km}^{2}$ in a 400 to $500-\mathrm{km}$ wide belt with precipitation isolines more or less parallel to lines of equal latitude. The growing season in this area is mono-modal with rains falling within the mid-June to October time period, with no rain falling from after October to mid-June. Other aspects of the Sahelian Zone and its transition zones are summarized in $[2,8]$.

The Sahel Zone has been a region of enormous interest to climate and environmental studies. It represents a unique area of the global land surface where systematic, unusual, and dramatic trends in rainfall occurred over the last 50-60 years to a minima in 1984, followed by a recovery from that time to the present. As such, the region provides a laboratory to study (1) if changes in land surface conditions influence regional climate; and (2) to investigate if extra-regional phenomena have influenced climate in this region ([1-7] and others). Due to this area's geographic location with regard to global and tropical circulation mechanisms, and its vast continental extent from west to east, this region is an excellent area to study global and regional atmospheric driving variables upon tropical precipitation. In addition, failure of the annual summer rainfall in a single year or persistence of failed rains over multiple years has broad consequences for inhabitants of the region $[9,10]$.

During the severe drought years in the late 1960 s to the $1980 \mathrm{~s}$, a decreasing number of surface climate observations made it difficult to assess the spatial extent, severity and impacts of drought. This was due to the lack of prioritization of meteorological observations and budget stress on the newly independent Sahelian countries. Since the early 1980s, land surface remote sensing has provided an excellent platform for broad observations of this region using measurements derived from polar-orbiting meteorological satellites [11,12]. The normalized difference vegetation index data derived from the National Oceanic and Atmospheric Administration (NOAA) Advanced Very High Resolution Radiometer (AVHRR) sensor was employed as a proxy for rainfall to routinely observe and document growing conditions over the region beginning in 1981 [11-17]. The use of this index was based on field studies that found a linear relationship between annual rainfall and integrated or summed growing season NDVI $[13,14]$ for areas with precipitation $<800 \mathrm{~mm} / \mathrm{yr}$. When systematically measured over time, the annually integrated NDVI can also be used to estimate annual biomass 
production or net primary production [10,18-20] and the distribution of vegetation cover types [13]. The NDVI has thus become a primary baseline for various monitoring and assessments studies over the Sahel ([17,21-25] among many others). We use the NDVI to represent photosynthetic capacity.

Our present study updates our previous studies [17,21-23] from Global Inventory Modeling and Mapping Studies (GIMMS) of Sahelian vegetation dynamics and trends using the normalized difference vegetation index data on based the GIMMS NDVI3g (1981-2012) data set [26]. Our focus is to (1) determine if there have been changes in the growing season NDVI and rainfall relationships over the past 32 years; (2) document NDVI trends over our study region using this non-stationary 32-year photosynthetic capacity data set; and (3) place these trends and patterns within the longer time scale of Sahelian rainfall variability from the 1950 s to the present.

\section{Study Area}

We focus our attention over four areas: Western, Central and Eastern Sahel (marked by blue lines in Figure 1) and the entire Sahel region (reported also in some figures as "All Sahel"; marked by the red line in Figure 1). The three sub-regions we selected to represent areas of the Sahel that are to a certain extent influenced by maritime conditions originating from the Atlantic (Western) and Indian Ocean (Eastern) as opposed to the extreme dry continental climate (Central), with the 100-200 mm/year precipitation isolines trending further south (Figure 2). We compare the three regions with the entire Sahel region (All Sahel) index, which was derived to facilitate comparison with conventional regional rainfall Sahel index [4-7]. We define the Sahel as the region with a long-term 200 to $600 \mathrm{~mm} / \mathrm{yr}$ precipitation on the south side of the Sahara, determined by the African Rainfall Climatology data set rainfall isolines [27]. The use of spectral vegetation indices like NDVI is limited below $150 \mathrm{~mm} / \mathrm{yr}$ precipitation due to a small signal from green vegetation and a large signal from the soil background $[15,28,29]$ and we avoid these areas.

Figure 1. Geographic extent of the Sahel zone and adjacent regions in sub-Saharan Africa. The principal Sahelian countries are named. The area enclosed with the red outline stretches from $20^{\circ} \mathrm{W}$ to $40^{\circ} \mathrm{E}$ and from $10^{\circ} \mathrm{N}$ to $20^{\circ} \mathrm{N}$ defines the Sahel region. Three sub-regions are outlined in blue from which we have extracted NDVI3g and precipitation time series: (1) the Western Sahel from $10^{\circ} \mathrm{W}$ to $5^{\circ} \mathrm{W}$ by $12^{\circ} \mathrm{N}$ to $17^{\circ} \mathrm{N}$; (2) the Central Sahel from $12^{\circ} \mathrm{E}$ to $17^{\circ} \mathrm{E}$ by $10^{\circ} \mathrm{N}$ to $15^{\circ} \mathrm{N}$; and (3) the Eastern Sahel from $32^{\circ} \mathrm{E}$ to $37^{\circ} \mathrm{E}$ by $10^{\circ} \mathrm{N}$ to $15^{\circ} \mathrm{N}$.

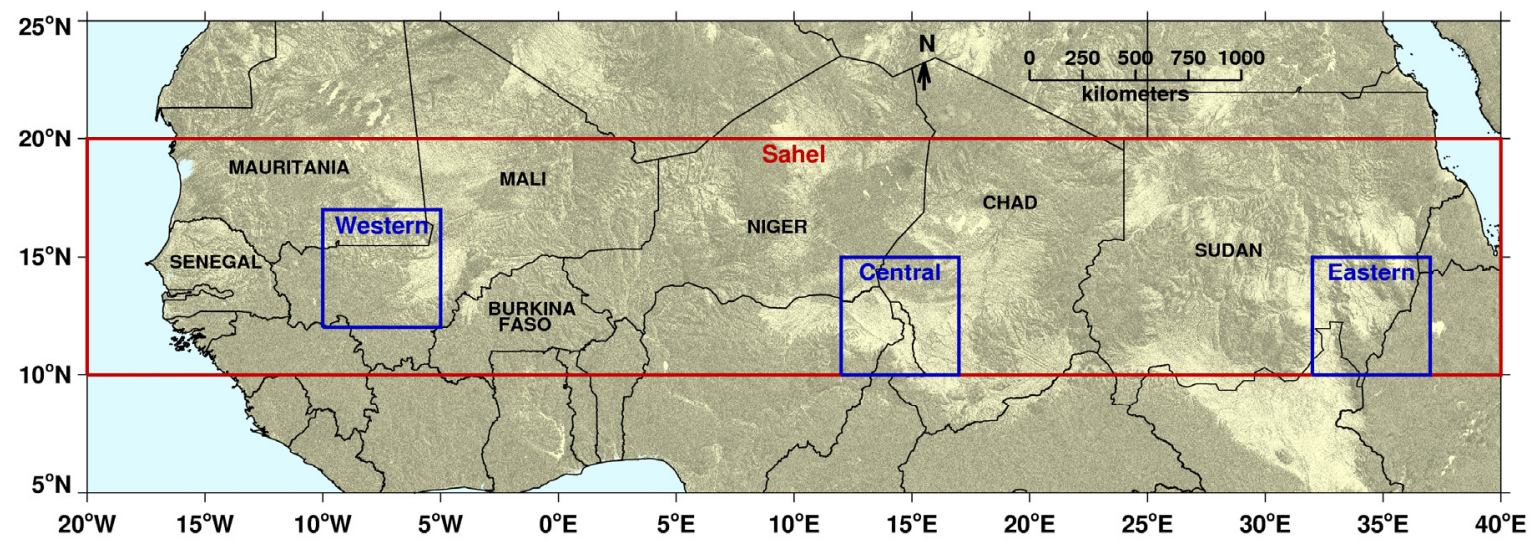


The Saharan-Sahelian transition zone is dominated by perennial grasses, the rainy season is usually 1.5 months duration, and the land use is exclusively pastoral nomadism. The Sahel proper is characterized by a Mimosoidae savanna of spiny acacia trees and the herbaceous cover is dominated by annual grasses. Land use is primarily grazing with some crop cultivation in depressions. The Sahelian-Sudanian transition zone is characterized by a Combretacae savanna with annual grass cover and a rainy season of 3-4 months. Land use is grazing and rain-fed agriculture. This transition zone has experienced increasing conversion of grazing land to agriculture, which can be marginal due to high variation in annual precipitation.

While open sparse grasslands and shrub lands dominate northern extremities of the Sahel, croplands, open woody vegetation, and deciduous shrubs characterize the southern parts [28]. In terms of vegetation composition, the region is dominated by various $\mathrm{C} 4$ type plants, accounting for roughly $80 \%$ of the herbaceous layer [30,31]. The vegetation is therefore highly adaptable to high air temperatures and has a high resistance to drought.

In general, rainfall amount, timing and distribution over the Sahel zone is controlled by the dynamics of the Inter-tropical Convergence Zone (ITCZ). Large-scale convection carrying moisture to great heights is primarily associated with the location of the ITCZ and forms the basis for the seasonal precipitation regime. The Sahelian rainy season is directly linked to what is known as the West African Monsoon, with a length of 1 to 4 months depending on latitude and the strength of the ITCZ in any given year. The annual peak in precipitation intensity is usually in August across the broad region and cessation of the rain occurs in October. The length of the rainy season decreases with increasing latitude; the season lasts approximately 1-2 months in the north and 4 months in the south, generally occurring between late June/July to September/October depending on the latitude [31]. On average $\sim 80 \%$ of the annual rainfall (200-300 mm/month) occurs between July and October (JASO) [32,33]. The annual long-term distributions of rainfall and NDVI correspond well, with relatively high NDVI of 0.4 occurring in November at the western and eastern extremities of the region that come under maritime influences from the Atlantic and Indian Ocean, respectively [22]. The geographic patterns of NDVI reflect the long-term rainfall distribution, for example at $10^{\circ} \mathrm{N}$ the rainfall is $\sim 800 \mathrm{~mm} / \mathrm{yr}$ and decreases progressively as one moves north, falling to $100 \mathrm{~mm} / \mathrm{yr}$ at $20^{\circ} \mathrm{N}$ as illustrated in Figure 2 .

Figure 2. Long-term mean annual normalized difference vegetation index (NDVI3g) with an overlay of long-term mean annual rainfall contours derived from the Africa Rainfall Climatology data set.

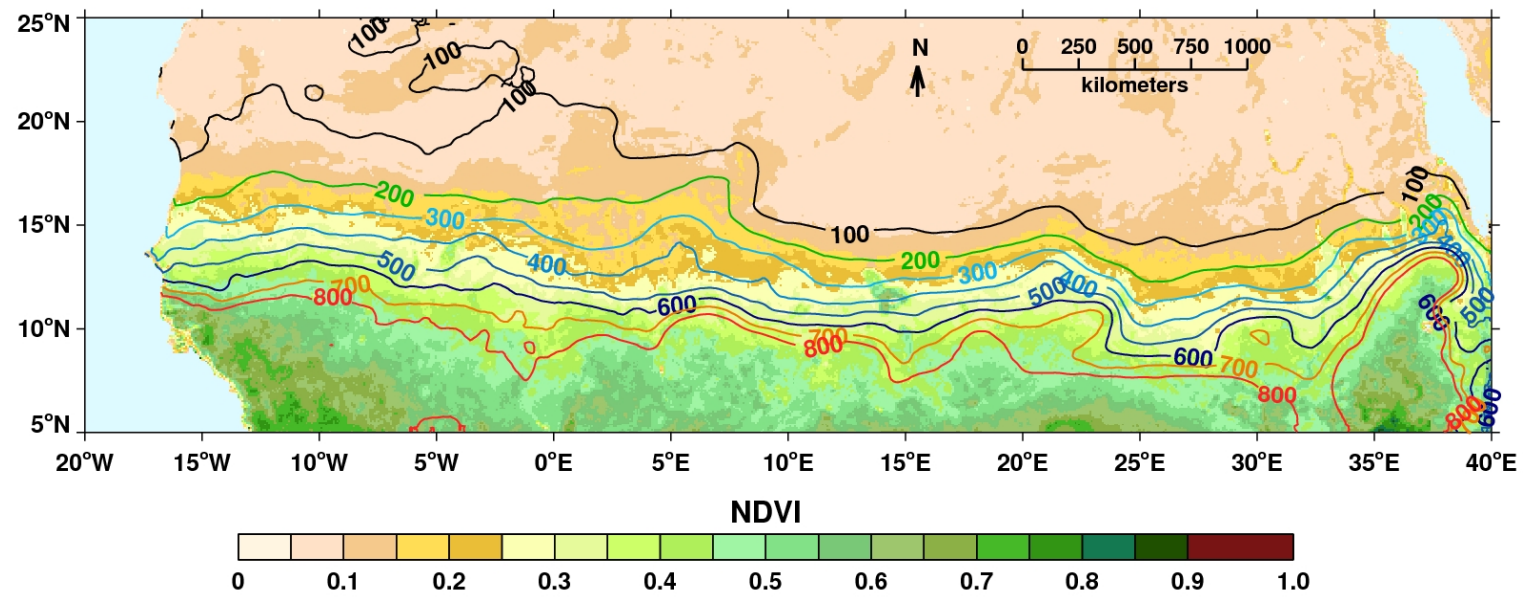




\section{Data}

\subsection{Vegetation Index Data-GIMMS NDVI Version 3}

The primary data set used in this study is the new non-stationary GIMMS NDVI version 3 (referred to as NDVI3g) [26] at $8 \mathrm{~km}$ spatial resolution from July 1981 to December 2012. This data set is a revised and updated extension of a previous NDVI version [32,33]. The NDVI3g includes measurements from all seven NOAA AVHRR instruments $(7,9,11,14,16-18)$ used to produce a global internally consistent NDVI product. The NDVI3g is a long-term data record produced to study vegetation photosynthetic capacity for land surface vegetation dynamics and non-stationary trend studies. As with the previous GIMMS NDVI version, these data have been processed using empirical mode decomposition to identify and remove artifacts from the NDVI time series, including solar zenith angle effects associated with orbital drift and inconsistencies in the AVHRR data among instruments $[26,34]$.

The NDVI3g data have a radiative-transfer volcanic aerosol correction for the El Chichon and Mt. Pinatubo stratospheric aerosol periods [34] and use maximum value composites to minimize effects of atmospheric water vapor, non-volcanic aerosols, and cloud cover [35,36]. NDVI3g constitutes a 32-year land surface record and is the first data set of its kind that is appropriate for long term studies of land surface trends in vegetation photosynthetic capacity, seasonality or phenology, and climate-vegetation couplings. The long-term mean of the NDVI3g for the Sahel and adjacent ecological zones and associated rainfall are shown in Figure 2.

\subsection{Rainfall Data}

We use three rainfall data sets for comparison with the NDVI time series data: (1) the Africa Rainfall Climatology (ARC) version 2 for 1983 to 2013; (2) the Variability Analyses of Surface Climate Observations (VASClimO) Version-1.1 for 1951 to 2000; and Sharon Nicholson's sixty-two ground station precipitation data used in Tucker and Nicholson [17].

\subsubsection{African Rainfall Climatology}

The Africa Rainfall Climatology version 2 is a gridded, daily 30-year (1983-2013) precipitation dataset at $0.1^{\circ} \times 0.1^{\circ}$ spatial resolution produced by NOAA's Climate Prediction Center. As with version $1 \mathrm{ARC}$, it is produced using an operational rainfall estimation algorithm [27], now updated to Rainfall Estimates Version 2 [37], with inputs from two sources: (1) 3-hourly geostationary infrared (IR) data centered over Africa from the European Organization for the Exploitation of Meteorological Satellites; and (2) quality controlled Global Telecommunication System gauge observations reporting 24-hour rainfall accumulations over Africa [27,37]. Version 2 employs improved calibration of IR data from all Meteosat First Generation satellite observations (1983-2005) to be consistent with other long-term datasets, such as the Global Precipitation Climatology Project and Climate Prediction Center Merged Analysis of Precipitation. Regional underestimations of daily and monthly rainfall occurring in some areas are attributed both to the unavailability of daily Global Telecommunication System gauge reports in real time and to deficiencies in the satellite estimate associated with precipitation processes 
over coastal and orographic areas, such as the Gulf of Guinea in West Africa and the East Africa highlands. As with the previous version of ARC, this new data set is used for real-time monitoring of daily precipitation for famine early warning [37] and a variety of climate studies [38]. The long-term mean ARC rainfall is shown in Figure 2, overlaid on NDVI long-term mean.

\subsubsection{Variability Analyses of Surface Climate Observations (VASClimO) Rainfall}

The VASClimO is a global data set of observed station precipitation produced by gridding homogeneity-checked station time-series of precipitation for the period 1951-2000 from 9343 selected stations with an almost complete coverage over the entire period. It provides a globally gridded total monthly precipitation from January 1951 to December 2000 at three resolutions: $0.5^{\circ} \times 0.5^{\circ}, 1.0^{\circ} \times 1.0^{\circ}$, and $2.5^{\circ} \times 2.5^{\circ}$, excluding Antarctica and Greenland because of lack of data [39]. We use the $0.5^{\circ} \times 0.5^{\circ}$ resolution version of these data in our study. The data have undergone quality control with respect to outliers, homogeneity, and interpolation; gridding is done as thoroughly as possible in order to obtain optimal results. However, due to data gaps it may not truly reflect the spatial and temporal precipitation in some areas. Nevertheless, this data set is useful for studies of climate variability on decadal time scales. The data are produced by a joint climate research project of the German Weather Service Global Precipitation Climatology Centre (GPCC) and the Johann Wolfgang Goethe-University Frankfurt Institute for Atmosphere and Environment-Working Group for Climatology. This 50-year precipitation data set is a contribution to the IPCC WG I Fourth Assessment Report (2007) [40]. Since this data set terminates in 2000, we have extended the VASClimO series using the ARC data set as a gap-filler for the period 2001-2012.

\subsubsection{Nicholson's Ground Station Rainfall Data}

Professor Sharon Nicholson at the Meteorology Department, Florida State University has assembled precipitation data from ground stations in sub-Saharan Africa for the period 1901 to 1994 [14,32]. A historical subset of the data for the period 1901-1984 is available from Research Data Archive at the National Center for Atmospheric Research, Computational and Information Systems Laboratory [41]. We use a subset of these for the period 1981-1994 which we obtained directly from Professor Nicholson for 62 stations with total annual precipitation $<800 \mathrm{~mm} / \mathrm{yr}$ within the Sahel, the same data used in [17]. We also use these data to determine the accuracy of the ARC and VASClimO precipitation for these specific geographical station locations.

\section{Methods}

\subsection{NDVI/Rainfall Analysis}

The relationship between growing season (July to October: JASO) integrated NDVI and rainfall was investigated to determine whether it had changed over time. We analyzed this relationship using three selected 10 year epochs (1) 1983-1992; (2) 1993-2002; (3) 2003-2012; and finally (4) for the entire period: 1983-2012. The 10 year intervals were selected to roughly correspond to the gradient of NDVI over the Sahel from the 1980 s period dominated by drought to the wet period during the mid-1990s and 2000s. We adjusted the start year of comparison to 1983 to coincide with the start of 
the ARC rainfall time series. We compared all land-based rainfall and NDVI observations covering the Sahel region with annual total rainfall from $200 \mathrm{~mm} / \mathrm{yr}$ to $600 \mathrm{~mm} / \mathrm{yr}$. The restriction on mean annual rainfall was designed to exclude both desert and non-rainfall limited regions. For the purposes of this study, we are interested only in the NDVI-rainfall relationship for semi-arid regions. We performed ordinary linear regressions of mean growing season July to October NDVI on total growing season ARC rainfall for each of the four time periods. To test for the influence of time period on the NDVI-rainfall relationship, we used the method of dummy regression [42]. The full regression model for 1983-2012 was defined as

$$
\mathrm{Y}=\mathrm{b}_{0}+\mathrm{b}_{1} \mathrm{X}+\mathrm{b}_{2} \mathrm{D}_{1}+\mathrm{b}_{3} \mathrm{D}_{2}+\mathrm{b}_{4} \mathrm{XD}_{1}+\mathrm{b}_{5} \mathrm{XD}_{2}
$$

where

$$
\begin{aligned}
& Y=\text { predicted NDVI } \\
& X=\text { observed rainfall } \\
& b_{i}=\text { regression coefficients } \\
& D_{1}=1 \text { for } 1993-2002,0 \text { otherwise } \\
& D_{2}=1 \text { for } 2003-2012,0 \text { otherwise }
\end{aligned}
$$

For the decadal periods the model reduced to

$$
\begin{aligned}
& \text { 1983-1992: } \mathrm{Y}=\mathrm{b}_{0}+\mathrm{b}_{1} \mathrm{X} \\
& \text { 1993-2002: } \mathrm{Y}=\left(\mathrm{b}_{0}+\mathrm{b}_{2}\right)+\left(\mathrm{b}_{1}+\mathrm{b}_{4}\right) \mathrm{X} \\
& \text { 2003-2012: } \mathrm{Y}=\left(\mathrm{b}_{0}+\mathrm{b}_{3}\right)+\left(\mathrm{b}_{1}+\mathrm{b}_{5}\right) \mathrm{X}
\end{aligned}
$$

We performed incremental F-tests to determine the significance of the rainfall main effect (null hypothesis $\mathrm{H} 0: \mathrm{b}_{1}=\mathrm{b}_{4}=\mathrm{b}_{5}=0$ ), the decadal main effect $\left(\mathrm{HO}: \mathrm{b}_{2}=\mathrm{b}_{3}=\mathrm{b}_{4}=\mathrm{b}_{5}=0\right.$ ), and the decadal/rainfall interaction effect $\left(\mathrm{H} 0: \mathrm{b}_{4}=\mathrm{b}_{5}=0\right)$; all tests rejected $\mathrm{H} 0$ at greater than 99 percent confidence. Finally we calculated the coefficient of determination $\left(\mathrm{r}^{2}\right)$ and the 95 percent confidence interval for predicted values for each decade and the full model.

\subsection{Standardization}

To further examine the relationship between growing season NDVI and rainfall, we computed standardized July to October values for NDVI3g (1981-2012), ARC rainfall (1983-2012), and VASClimO rainfall (1951-2000) for the study region by subtracting the population mean and then dividing the difference by the population standard deviation $[43,44]$.

where

$$
\mathrm{z}=(\mathrm{x}-\mu) / \sigma
$$

$\mathrm{x}$ is the July to October value to be standardized

$\sigma$ is the standard deviation of all July to October values

$\mu$ is the mean of all July to October values

$\mathrm{z}$ is the standardized value, or $\mathrm{z}$-score.

The population therefore constitutes all the July to October values for an individual pixel location for each data set, i.e., the NDVI3g, ARC and VasClimo data. The z-score is the deviation of the individual pixel values in the time series from their mean values expressed in number of standard 
deviations. The standardization procedure converts different data sets to a uniform scale, enabling direct comparison between measurements of NDVI and rainfall, and provides an insight on how "typical" an observation is compared to the population. This method has been employed in various global and Sahel studies [45-47] to describe trends in vegetation and desertification using NDVI and rainfall time series data.

\subsection{Trend Analyses}

We computed temporal trends for the NDVI and rainfall z-scores respectively using linear least square regression over the common 1983-2012 period. This technique is a robust method of examining long-term trends in a temporal sequence of data that departs from the short-term annual fluctuations $[46,48]$. In this case, the magnitude and direction of the slope of the trend line can be interpreted as a measure of the possible improvement or decline in vegetation/rainfall conditions over time.

\section{Results}

\subsection{NDVI3g and ARC Rainfall Relationship}

We compared the NDVI3g data set against the ARC rainfall data using ordinary least squares linear regression. Previous studies have shown sensitivity of Sahelian vegetation to precipitation at both seasonal and inter-annual time scales [14]. These earlier studies were based on sample NDVI extracted and averaged coincident with rain-gauge station locations [17]. Our findings here compare entire fields of NDVI and satellite based rainfall estimates. In order to gauge whether the relationship has changed over the last 30 years as rainfall amounts have increased, we divided the time series into three epochs as outlined in the methods section. As would be expected, the results show a positive correlation between NDVI and rainfall for all the epochs with coefficients of determination as follows: $\mathrm{r}^{2}=0.37$ for 1983-1992; $\mathrm{r}^{2}=0.36$ for $1993-2002, \mathrm{r}^{2}=0.38$ for 2003-2012 and for the entire period 1983-2012, $\mathrm{r}^{2}=0.38$. All regression coefficients were significant at $p>0.01$ as shown in Figure 3 .

These coefficients are within the same range as recent findings by Fensholt et al. [25], for the growing season using the Merged Analysis of Precipitation rainfall data set. The intercept of the regression line shifts toward zero by each decade, and the slope increases slightly. This indicates a tightening of the NDVI rainfall relationship over time with the increase in growing season rainfall. While these relationships are gross representations of the entire Sahel, they do point to the importance of rainfall in this semi-arid ecosystem in regulating the seasonal, inter-annual, and long-term variability patterns of vegetation. 
Figure 3. Scatterplots of average July to October NDVI vs. July to October rainfall by decadal epochs (A, B, and C); and for the entire common period (D). The dashed lines represent the $95 \%$ confidence interval for the predicted NDVI.
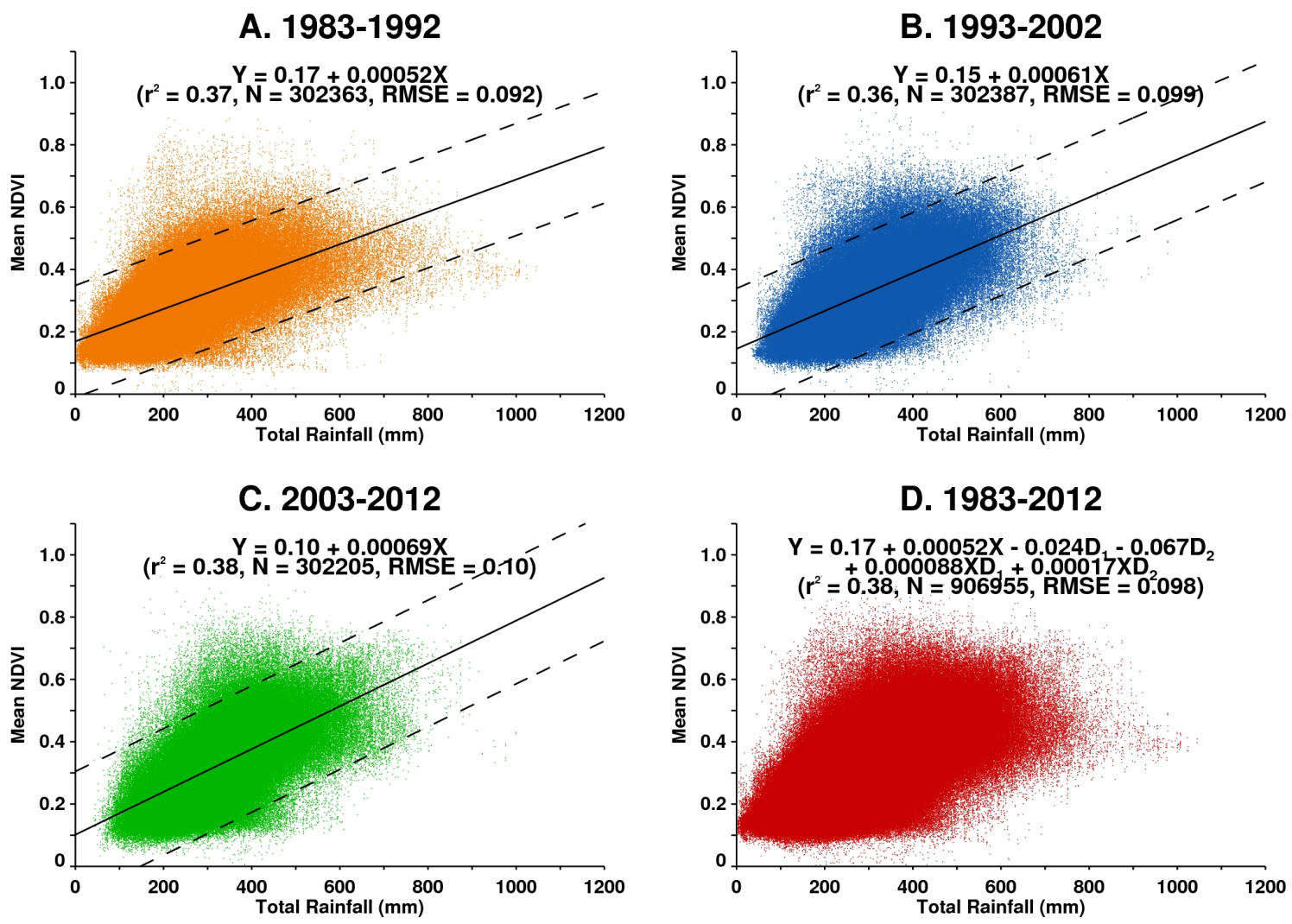

We confirmed the accuracy of the African Rainfall Climatology and Variability Analyses of Surface Climate Observations precipitation data, by comparing these and the Nicholson Sahelian-Sudanian ground meteorological station precipitation data from 1981 to 1994 used in Tucker and Nicholson [17] to coincident NDVI data. Only locations with 1981 to 1994 average precipitation $<800 \mathrm{~mm} / \mathrm{yr}$ for the Nicholson data were used. A three by three pixel NDVI3g average was computed centered on each ground station and averaged for the July to October time period. The African Rainfall Climatology precipitation was averaged for each ground station for the three by three $0.1^{\circ}$ pixels centered on the station, and the Variability Analyses of Surface Climate Observations precipitation was used for the $0.5^{\circ}$ grid cell containing each ground station, both by year. These three precipitation data sets were then correlated with the associated NDVI3g data after all station location values were averaged for their respective time periods. We found very similar relationships with NDVI3g data for the three precipitation collections with the $\mathrm{r}^{2}$ values of $0.90,0.91$ and 0.88 (Figure 4A-C). Furthermore, when you average precipitation and associated NDVI data for the $<800 \mathrm{~mm} / \mathrm{yr}$ Sahelian-Sudanian zones, as we did for the 1981 to 1994 or 1983 to 1994 time periods, the data scatter in Figure 3 is substantially reduced. Our explanation for this is the inter-annual variability in the precipitation data is reduced, minimizing the effects of seasonal variability in rainfall timing and intensity, and moving the NDVI3g-precipitation toward a more accurate representation of "effective rainfall". That is, the rainfall that soaks into the ground and is used for plant growth. 
Figure 4. Linear correlations with NDVI3g and precipitation data from 62 ground stations in Sahelian-Sudanian Africa with 1981 to 1994 (upper and bottom) and 1983 to 1994 (middle) average precipitation $<800 \mathrm{~mm} / \mathrm{yr}$. Note the very similar results for NDVI3g and the respective precipitation data sets for $(\mathbf{A})$ the Nicholson ground station data used in [17]; (B) the African Rainfall Climatology; and (C) the Variability Analyses of Surface Climate Observations. The African Rainfall Climatology data start in 1983 and the Nicholson ground station data end in 1994.

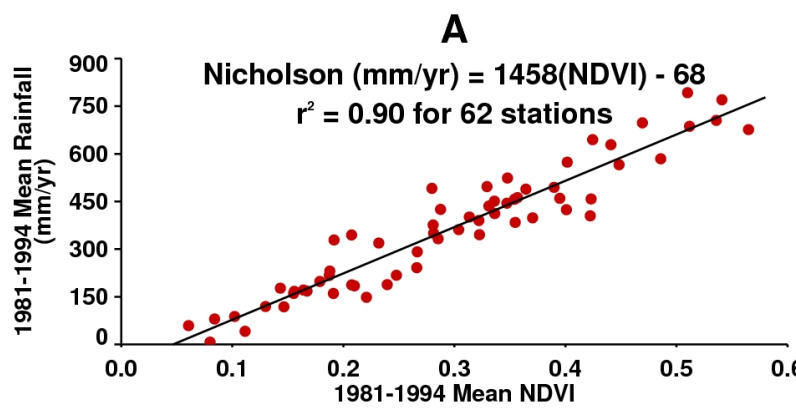

B

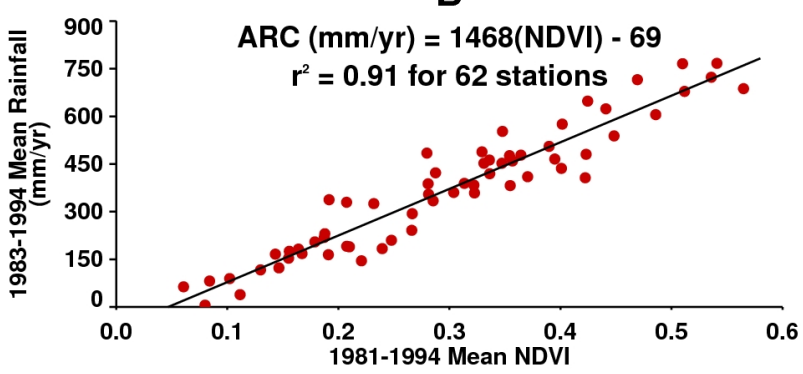

C

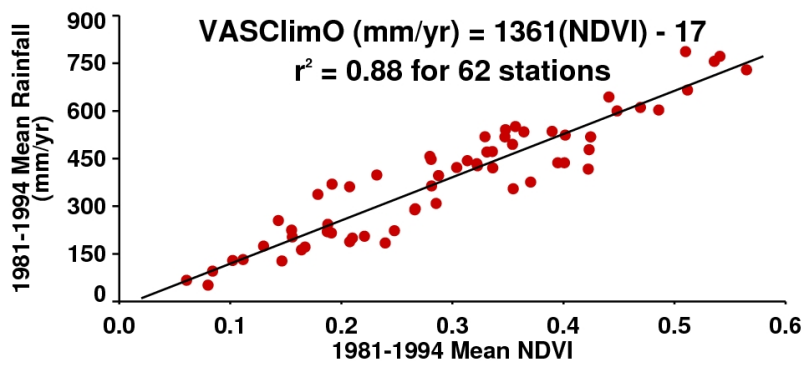

\subsection{Spatio-Temporal Patterns: 1981-2012}

Variations in original and standardized NDVI3g values for the 32-year time series are presented in a hovmoller diagram in Figure 5. Seasonality of vegetation is represented by the waxing and waning of NDVI annually across the longitudes through the years with the growing season marked by the extent of $\sim 0.35-0.65$ NDVI values (Figure 5A). The extension of this "green wave" across the entire longitudinal region is an indicator of wet years, for example 1981, 1994, 1999 and 2012. Periods when this wave is discontinuous, narrow or terminates (particularly at $\sim 5^{\circ} \mathrm{W}$ ) represents poor rainfall years or drought periods, for example in 1984, 1988, and 2003. Figure 5B shows the standardized departure patterns, clearly revealing the extent and persistence of wet and dry years. The well documented drought period from 1983 to 1988 is clearly defined with the signature 1984 extreme drought event being a prominent feature of the time series. The subsequent period from 1994 to 2002 is dominated by 
positive departures in NDVI with values a high as +3 standard deviations from the mean in 1994, 1999, 2000 and 2001. The period from 2003 to 2012 represents more normal conditions interspersed with a number of wet and dry events including a pronounced drought period in 2004-2005 and two region wide wet events in 2007 and 2012. Sub-regional differences also stand out, for example in 1993 when the eastern Sahel is wet and the western Sahel is dry and 1982 when the western Sahel is wet and the central to eastern Sahel is dry. In general, this time-space representation of the Sahel shows a trend from the dry period in the 1980 s to wetter and greener conditions in the last two decades.

Figure 5. Time-longitude section of monthly NDVI from July 1981 to December 2012 averaged between $10^{\circ} \mathrm{N}$ to $20^{\circ} \mathrm{N}$ from $18^{\circ} \mathrm{W}$ to $40^{\circ} \mathrm{E}$. (A) monthly evolution of NDVI; and (B) the corresponding monthly NDVI z-scores showing dry conditions in the 1980s and predominantly greener than normal conditions from 1994 to 2012.

A. NDVI

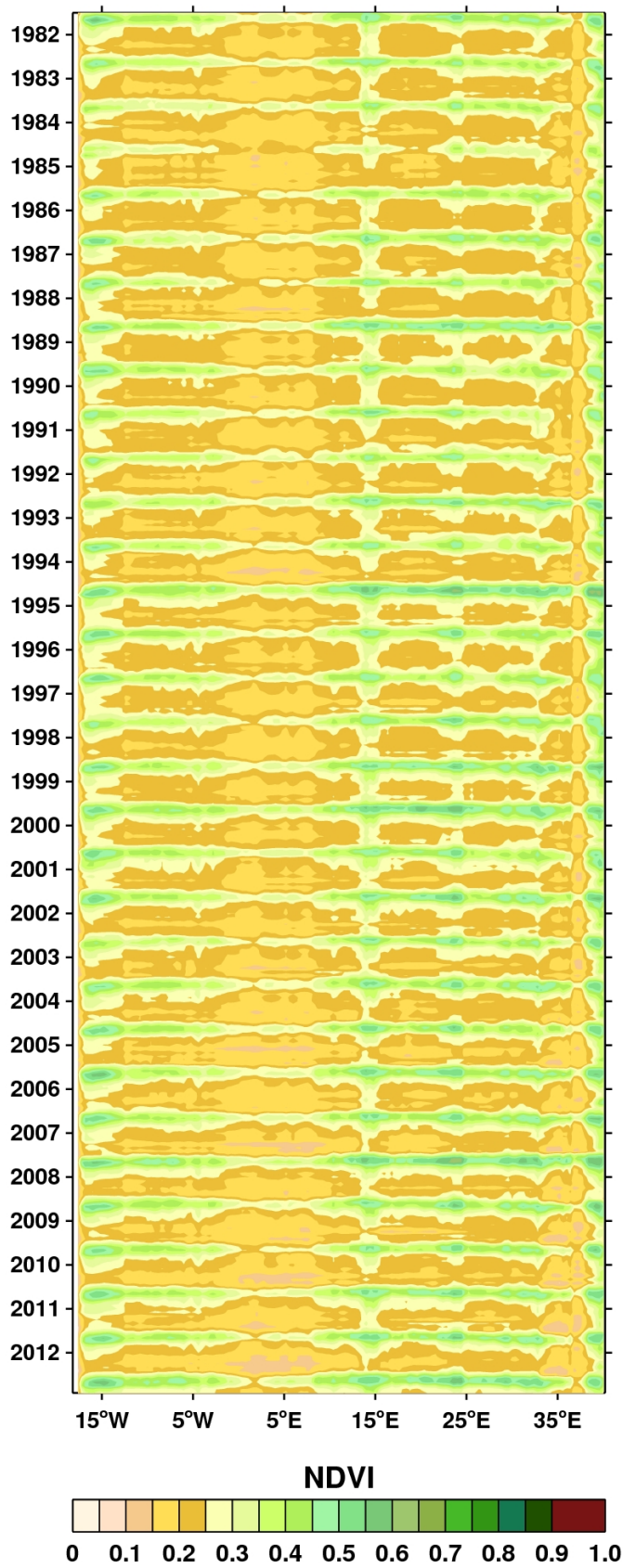

\section{B. Standardized NDVI}

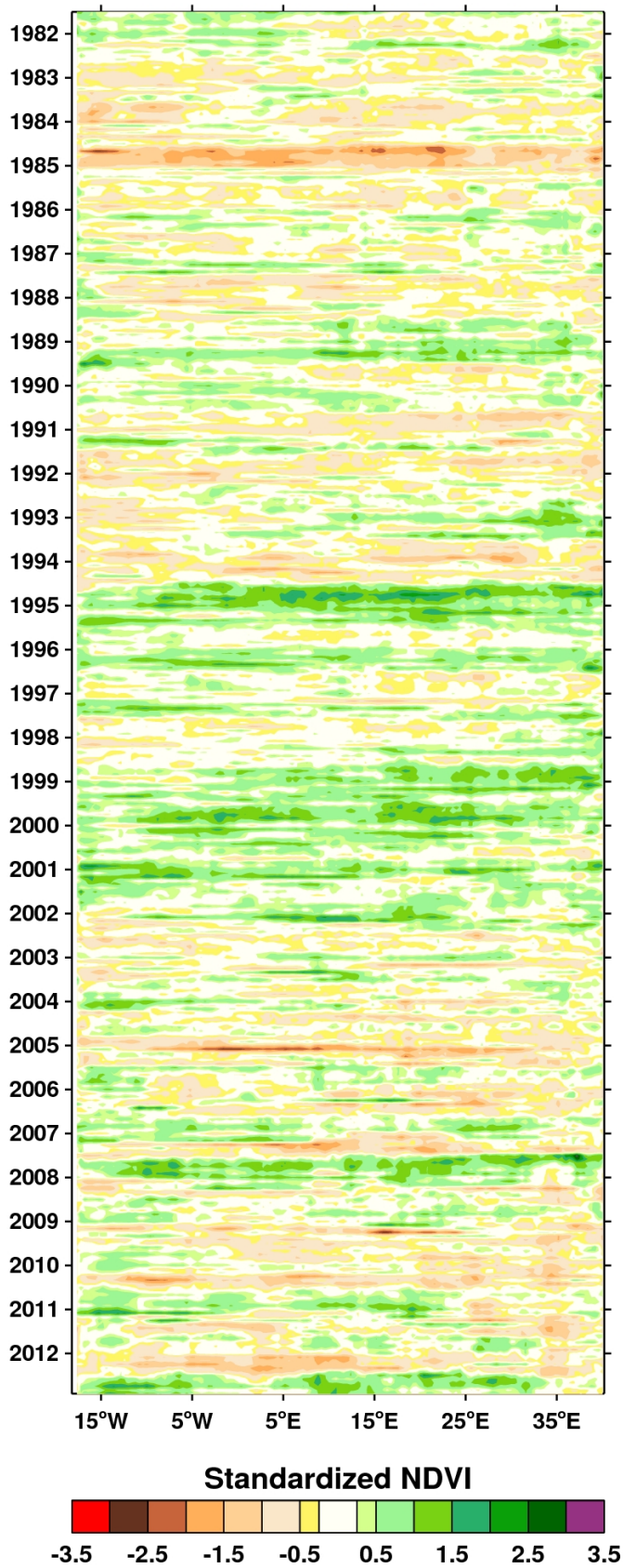


We selected three growing seasons on the basis of the highest/lowest NDVI anomaly or the highest/lowest rainfall anomaly for further examination (Table 1). The year 1984 (ranked 32th in both NDVI and rainfall anomaly) was marked by a well documented and extreme continental-scale drought across sub-Saharan Africa [9,49], while 1994 ranked 1st by NDVI and 5th by rainfall and 2012 ranked 3rd by NDVI and 2nd by rainfall and were unusually high photosynthetic capacity and wet years. The spatial patterns of the departures in NDVI and rainfall of the selected years are given in Figure 6 below. The entire region bounded by $5^{\circ} \mathrm{N}$ and $18^{\circ} \mathrm{N}$ had extreme negative departures in NDVI with z-score values in the range of -1.5 to -3.5 in 1984 (Figure 6A). This was a result of extreme precipitation deficit with most of the region above $5^{\circ} \mathrm{N}$ receiving shortfalls of between $100 \mathrm{~mm} / \mathrm{yr}$ at northern extremes of the region, and between 200 to $500 \mathrm{~mm} / \mathrm{yr}$ in the central band of the region (Figure 6B).

Table 1. Rankings of the area-averaged NDVI and rainfall z-scores for the entire Sahel from the highest photosynthetic capacity (highest positive NDVI anomaly) or wettest (highest positive rainfall anomaly) to the lowest of these variables.

\begin{tabular}{|c|c|c|c|c|}
\hline Year & Standardized NDVI & NDVI Rank & Standardized Rainfall & Rainfall Rank \\
\hline 1983 & -0.44826 & 28 & -0.97592 & 29 \\
\hline 1984 & -1.20077 & 30 & -1.14989 & 30 \\
\hline 1985 & -0.3956 & 27 & -0.03991 & 18 \\
\hline 1986 & -0.10209 & 19 & 0.148109 & 12 \\
\hline 1987 & -0.5395 & 29 & -0.55186 & 26 \\
\hline 1988 & 0.186508 & 9 & 0.505977 & 6 \\
\hline 1989 & -0.02471 & 17 & -0.24519 & 21 \\
\hline 1990 & -0.32851 & 23 & -0.96913 & 28 \\
\hline 1991 & -0.3818 & 25 & -0.65913 & 27 \\
\hline 1992 & 0.039235 & 14 & -0.49558 & 24 \\
\hline 1993 & -0.2263 & 22 & -0.33219 & 23 \\
\hline 1994 & 0.988894 & 1 & 0.516035 & 5 \\
\hline 1995 & 0.155848 & 11 & -0.02852 & 17 \\
\hline 1996 & 0.046132 & 13 & -0.29501 & 22 \\
\hline 1997 & 0.006414 & 16 & -0.20675 & 19 \\
\hline 1998 & 0.292202 & 6 & 0.454949 & 7 \\
\hline 1999 & 0.858483 & 2 & 1.082127 & 1 \\
\hline 2000 & 0.164487 & 10 & -0.00573 & 16 \\
\hline 2001 & 0.33372 & 5 & 0.085133 & 14 \\
\hline 2002 & -0.34423 & 24 & -0.21111 & 20 \\
\hline 2003 & 0.233602 & 8 & 0.547516 & 4 \\
\hline 2004 & -0.1171 & 20 & -0.51607 & 25 \\
\hline 2005 & 0.24754 & 7 & 0.316836 & 10 \\
\hline 2006 & -0.06519 & 18 & 0.314985 & 11 \\
\hline 2007 & 0.611959 & 4 & 0.338364 & 9 \\
\hline 2008 & 0.047664 & 12 & 0.103641 & 13 \\
\hline 2009 & -0.38797 & 26 & 0.358394 & 8 \\
\hline 2010 & 0.030585 & 15 & 0.928349 & 3 \\
\hline 2011 & -0.1439 & 21 & -0.00511 & 15 \\
\hline 2012 & 0.730193 & 3 & 0.986673 & 2 \\
\hline
\end{tabular}


Figure 6. Spatial departure patterns in NDVI (left) and Rainfall (right) for three selected extreme years $(\mathbf{A}-\mathbf{F})$. Note the greater spatial coherence of the NDVI3g data compared with the rainfall data.

\section{A. 1984 NDVI}

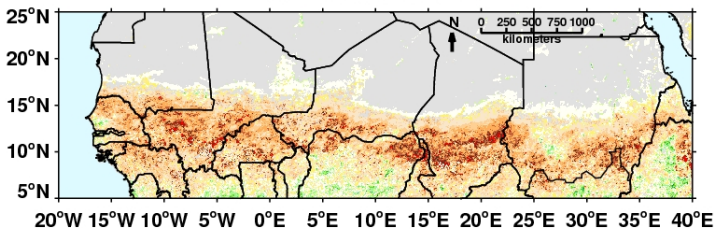

C. 1994 NDVI

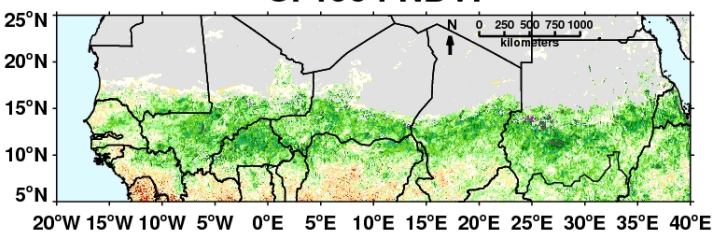

E. 2012 NDVI

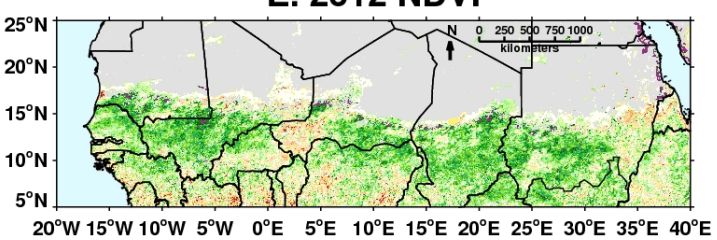

Standardized NDVI

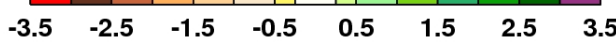

\section{B. 1984 Rainfall}

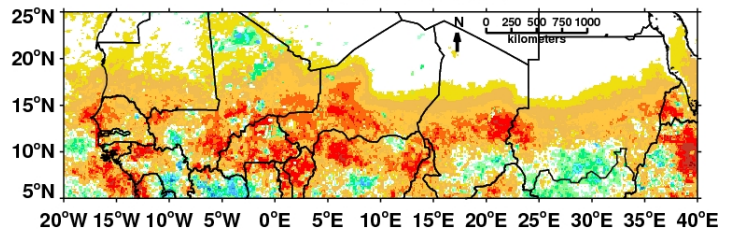

D. 1994 Rainfall

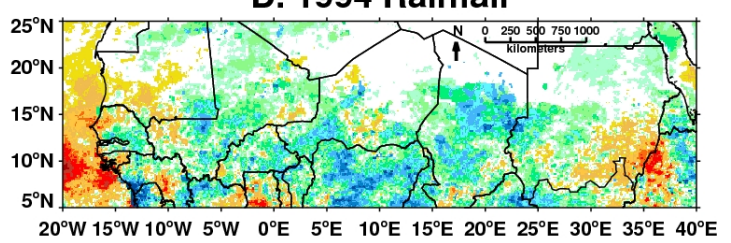

F. 2012 Rainfall

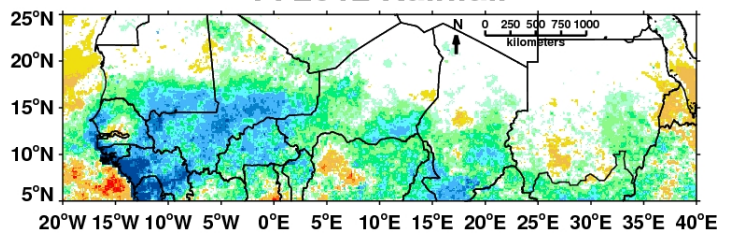

Rainfall Anomaly (mm)

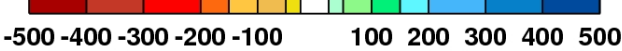

These patterns were largely reversed in 1994 (Figure 6C) and 2012 (Figure 6E), with positive NDVI z-score departures ranging between +1.0 to high as +3.5 in some localized areas in Mauritania, Mali, Niger, Chad and western Sudan with associated with excess rainfall of between 100 to $500 \mathrm{~mm} / \mathrm{yr}$ (Figure 6D). The growing season of 1994 marked the beginning of a trend toward a greener and wetter Sahel and associated transition zones (Figure 5). Other documented evidence [50] shows that the rainfall during this season was the highest since 1967 and was most prominent in the central and western half of the region. The 2012 growing season was even wetter than 1994 with prominent flooding in several locations, especially the western parts of the Sahel region (Figure 6F). The 2012 rainfall season has been recently ranked as the third wettest (2nd wettest over the last 32 years) over the region, especially over the western half since 1948 and marks a continuation of the increased rainfall trend that has been observed since beginning of the 21 st century $[51,52]$.

Overall, the spatial patterns of NDVI and rainfall reveal some unique characteristics. The regional rainfall has a tendency to show a high level of spatial variability especially at the extreme amounts. This variability is an indicator of the underlying rainfall producing mechanisms, which involve westward-propagating mesoscale disturbances, termed cloud clusters, associated with squall lines or tropical storms. These cloud clusters result in heavy rainfall in some locations and little or rain in others $[53,54]$. NDVI anomalies on the other hand, are more spatially continuous, reflecting the tendency for semi-arid ecosystems on to respond to even small amounts of rainfall during the growing season. The patchiness in NDVI occurring in some locations during both the dry and wet seasons reflects both the "effective rainfall" in those years and, to a lesser extent, the influence of background soil conditions on reflectance in areas with sparse vegetation or areas where the plant species do not 
respond to rainfall during a single season [25]. Additionally, the Sahelian landscape, especially the Western Sahel, is dominated by the "brousse tigree" vegetation type characterized by alternating sand dune remnants interspersed with lower-lying inter-dune areas where runoff collects and woody vegetation is more prevalent and agriculture is practiced [55]. Such formations produce spatial heterogeneity in satellite vegetation indices as shown here. We calculate the 1984 severe July to October drought had an average rainfall of $223 \mathrm{~mm} / \mathrm{yr}$ for the 200 to $400 \mathrm{~mm} / \mathrm{yr}$ area of $>2.5 \mathrm{million} \mathrm{km}^{2}$ and the wettest year of 1994, with a July to October standardized NDVI $>0.5$, had an average rainfall of $406 \mathrm{~mm} / \mathrm{yr}$ for the same large area.

\subsection{Time Series and Spatial Trends}

In order to examine time series anomaly patterns during the growing season, we extracted NDVI3g and ARC rainfall z-scores for four regions: (1) Western Sahel; (2) Central Sahel; (3) Eastern Sahel; and (4) the entire Sahel region as defined in Figure 1. Overall, the NDVI time series (Figure 7) showed consistent patterns with a trend toward positive or higher photosynthetic capacity conditions starting in 1994 from negative values in the 1981 to 1993 time period. For the Western Sahel and Central Sahel, $\sim 50 \%$ of the growing seasons (16 of 32) were normal to above normal (Figure 7A,B). For the Eastern Sahel, $56 \%$ of the growing seasons (18 of 32) were normal to above normal (Figure 7C). From the 1980 s to the early 1990s, the western and eastern Sahel were dominated by depressed vegetation growing conditions from reduced rainfall, with the peak of the drought in 1984. The Eastern Sahel showed a more or less similar pattern, however the period from 1985 to 1989 was marked by positive departures in NDVI and there was a brief return to drought conditions in the 1990-1993 time frame. The droughts of 1984 and 1991-1992 were most severe for the eastern region, with NDVI and rainfall departures of 1.0 to 1.5 standard deviations below the mean.

The 1991 to 1992 drought period was part of the large-scale severe drought that affected Eastern Africa and extended into Sudan [56-58]. Like the rest of the Sahel Zone in the east, the period from 1994 to 2007 was dominated by positive departures in NDVI; however, 2008-2012 was dominated by below normal NDVI and rainfall conditions, an extension of the recent drought in eastern Africa. In part, the pattern of NDVI and rainfall departures over the Eastern Sahel are associated with the meteorological forcings that influence greater Eastern Africa, in particular the variability in sea surface temperature in the western equatorial ocean and ENSO, with its attendant impacts on rainfall [57-60]. The Sahel regional time series integrates and smoothes out differences among the three regional time series, with 53\% (17 of 32) of the growing seasons at normal to above normal NDVI (Figure 6D). Three years distinctly stand out: the severe drought in 1984 and the positive departures in 1994 and 2012. Overall, the aggregate Sahel time series mirrors the observed trends in the regional time series: the Sahel has become greener and wetter in the last 20 years, since a turn to wetter conditions starting with the 1994 growing season [50,51]. As a whole, there is coherent temporal correspondence between NDVI and rainfall anomalies during the predominantly dry years (1983 to 1993: $\mathrm{r}=0.72$, $p<0.05, n=11)$ and the wet years (1994 to 2012: $\mathrm{r}=0.59, p<0.05, n=19)$. 
Figure 7. Regional departure patterns in NDVI and African Rainfall Climatology precipitation for three selected regions and the entire Sahel region for the period July to October (JASO) (A) Western Sahel; (B) Central Sahel; (C) Eastern Sahel; and (D) entire Sahel Zone. All NDVI and African Rainfall Climatology anomalies are positively correlated: for the Western Sahel $r=0.67$; for the Central Sahel $r=0.77$; for the Eastern Sahel $\mathrm{r}=0.54$, and for the entire Sahel region $\mathrm{r}=0.76$, all at $p<0.050$.

A. Western

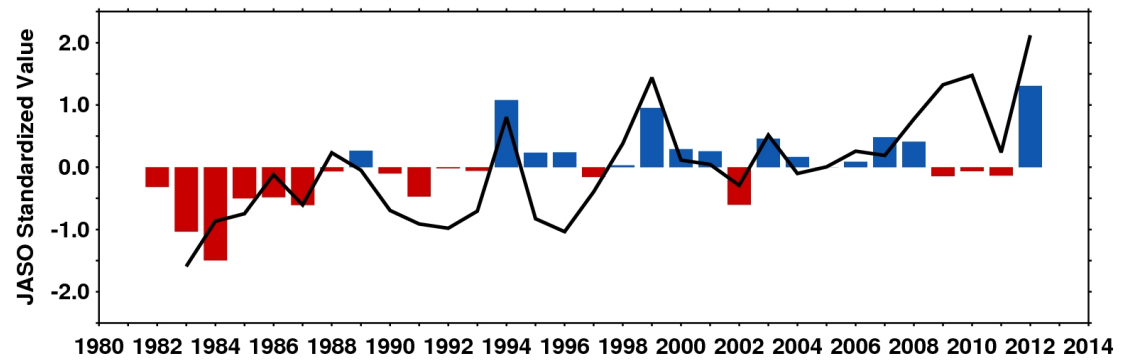

B. Central

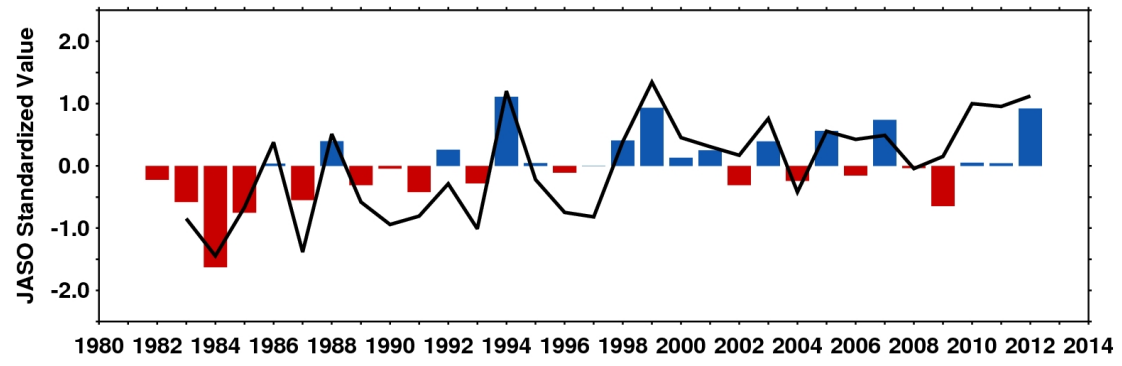

C. Eastern

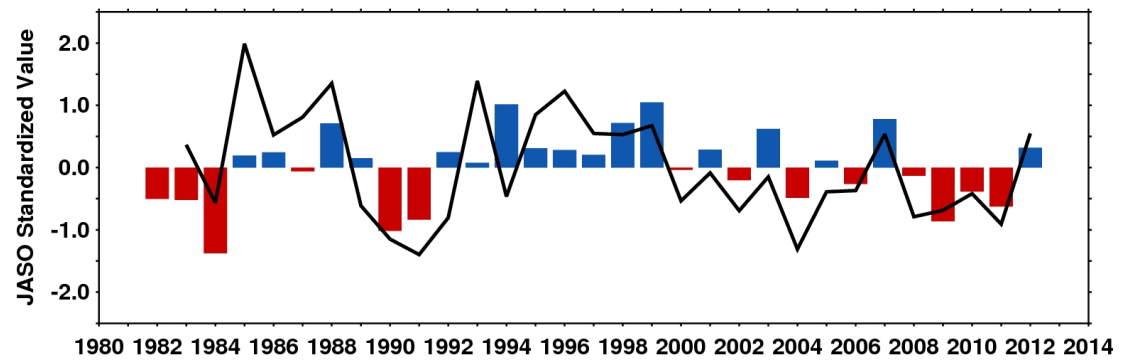

D. All Sahel

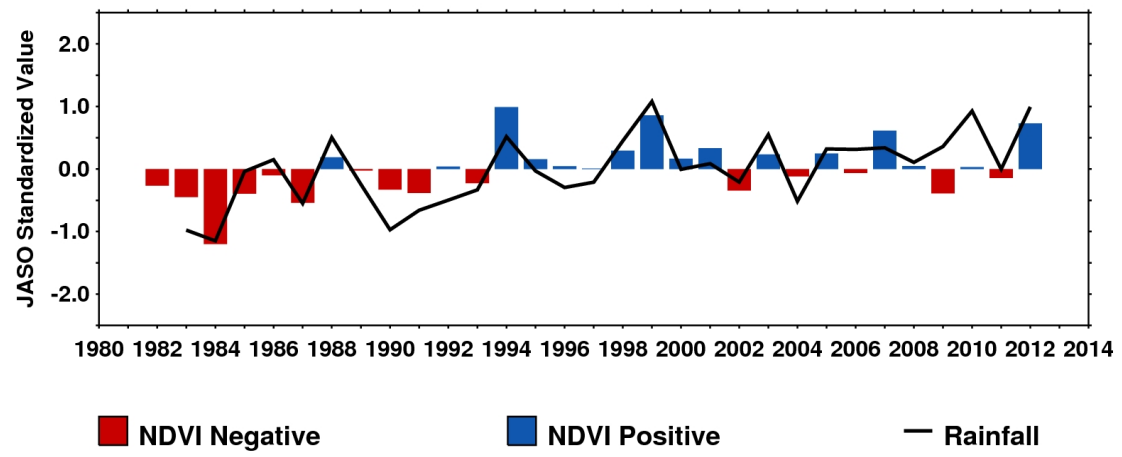

In order to assess spatial trends in growing season NDVI and ARC rainfall, we computed the temporal trends of the z-scores of both data sets using linear least square regression of each quantity with respect to time. The results are shown in Figure 8A for NDVI3g and Figure 8B for the ARC data. 
The trend maps represent the linear regression coefficient or slope for the standardized July to October values by year. The overall patterns show a positive trend in NDVI during the growing season over the last 32 years, confirming that which was reported for the previous version of the NDVIg data set $[22,23,46,47,61]$. The positive trends in NDVI were concentrated in latitude bands between $10^{\circ} \mathrm{N}$ and $16^{\circ} \mathrm{N}$ in the Western Sahel region, and $5^{\circ} \mathrm{N}$ and $15^{\circ} \mathrm{N}$ in the Central and Eastern Sahel for areas that receive between 200 and $600 \mathrm{~mm} / \mathrm{yr}$ rainfall. The ARC rainfall positive trends were dominant over the Western Sahel and narrowed toward the Central Sahel, where the trends changed from slightly positive to insignificant at $\sim 16^{\circ} \mathrm{E}$. On the border region between Sudan and Ethiopia, negative rainfall (insignificant NDVI) indicates a drying trend over time. While we don't a have a conclusive explanation for the slight divergence in the trends, we can speculate that the negative in rainfall trend is due to more recent droughts 2008-2012 over the eastern region (Figure 7C) and that vegetation in this region that is at the confluence of the Blue Nile and White Nile is well watered from the drainage upstream in the East African highlands and hence the NDVI trend is not pronounced under recent diminished rainfall conditions. One area that showed a negative trend in NDVI is Southwestern Niger in the area surrounding Niamey (marked in blue on Figure 8A). This localized trend may be due to local land use or land cover change, in particular due to reported severe land degradation and soil erosion in this area of Niger $[62,63]$ These two locations require further investigations using Landsat or commercial satellite data to determine the proximal causes.

Figure 8. July to October trends in z-scores for (A) NDVI3g for 1981-2012; and (B) African Rainfall Climatology precipitation for 1983-2012, showing positive trends in NDVI across the Sahelian region and in rainfall from the Western to Central Sahel. The eastern region shows an in insignificant trend, but with rainfall showing a negative/drying trend at the eastern edge.
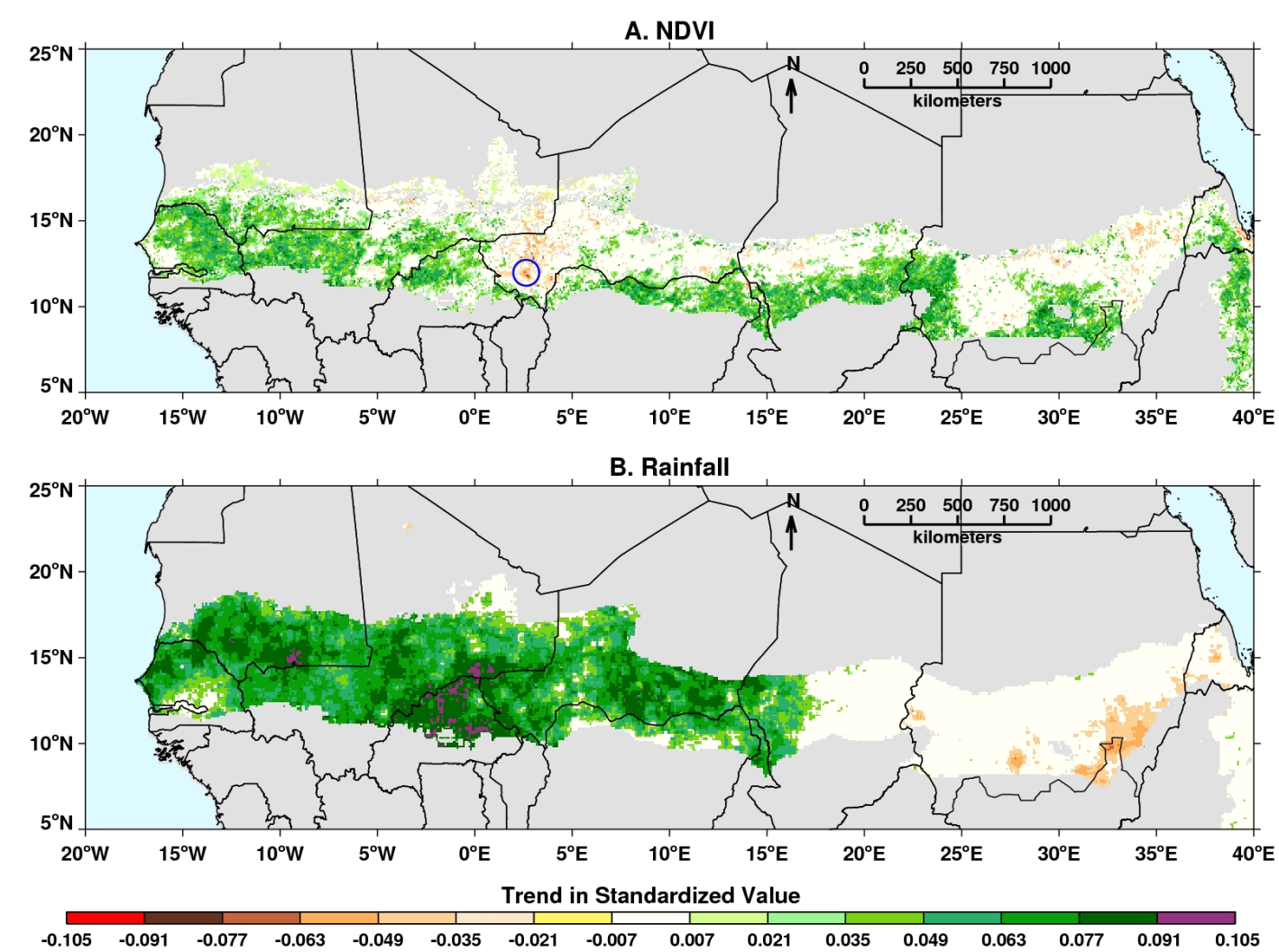


\subsection{NDVI3g Time Series in the Context of Long-Term 60 Year Rainfall Variability}

In the context of the long-term climate dynamics of the Sahel since 1951, the NDVI3g forms a useful and spatially coherent non-stationary data set that can be used to compare conditions from 1981 to the present against other climate records. Figure 9 shows the growing season NDVI3g z-scores compared to the long-term growing season rainfall z-scores computed from the VASClimO rainfall data set from 1950 to 2000, complimented by the ARC rainfall data from 2001-2012, for the entire Sahel region. Rainfall slowly and systematically declined starting in the 1950s and reached a minimum in 1984, at $\sim 1.5$ standard deviations below the mean. During the 1982-1987 time period, the whole semi-arid sub-Saharan area experienced more extreme dry conditions than the prior extreme drought of 1971 to 1973 [64]. Drought conditions persisted through the 1980s to 1993, except for one wet season in 1988. This persistence of drought is very well captured by the NDVI departures, with a close agreement between NDVI and rainfall z-scores during the 1982 to 1987 period. Drought conditions were ended by the remarkably wet season of 1994, with positive departures in rainfall and NDVI in the range of $\sim+0.6$ to +1.0 standard deviations above the long-term mean, equivalent to the wetter period in the mid-1960s. The mid-1990s marked the beginning of continued wetter growing seasons, starting in 1994, with positive anomalies in vegetation conditions, except in 2002 and 2004. The comparison between the ARC rainfall and NDVI3g for their common period 1983 to 2012 shows a high and significant positive correlation of $\mathrm{r}=0.76(p<0.05)$, indicating the close coupling between rainfall and vegetation photosynthetic capacity over the region.

Figure 9. Time series of VASClimO rainfall from 1951 to 2000, African Rainfall Climatology precipitation z-scores for 2001-2012, and NDVI3g z-scores for 1981-2012. NDVI3g captures the drier period of 1981-1993 and the wetter period from 1994 to 2012, in concert with the rainfall time series. The number of positive anomalies $>0.5$ standard deviation increased significantly for both NDVI and rainfall from 1994 to 2012 compared with the previous 24 years from 1970 to 1993.

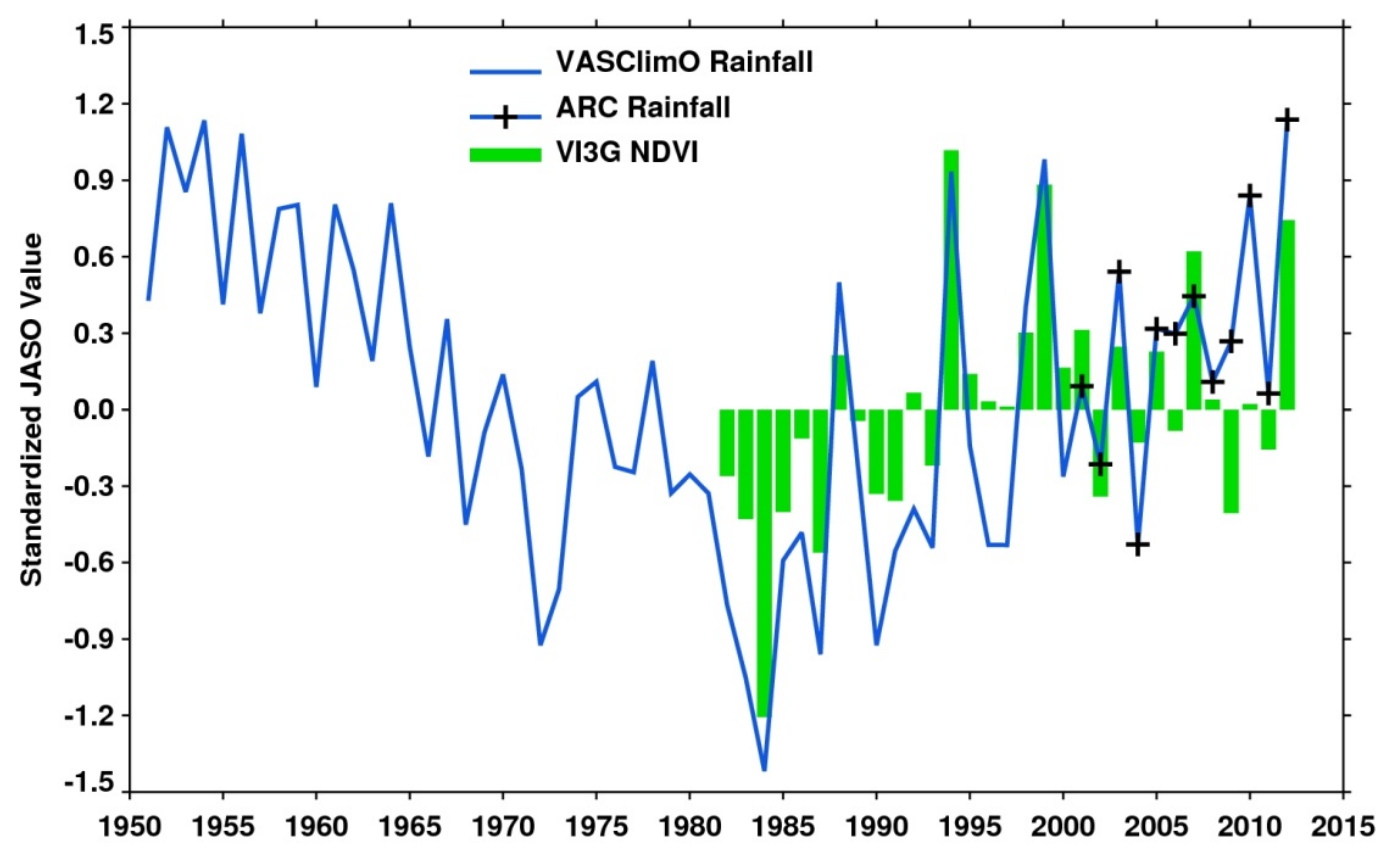




\section{Conclusions}

We confirm the NDVI3g 32-year time series data set can be used as a non-stationary land surface climate data record in a semi-arid environment where detailed ground-based meteorological data can be lacking. Unlike many short comings that have been encountered in the immediate past with spatially incomplete and temporally discontinuous surface observations of rainfall, the NDVI3g data sets offers a systematic and spatially continuous mapping of land vegetation photosynthetic capacity that is a quantitative non-stationary climate data record. Our examination of the 32-year NDVI3g record identified and quantified the extreme drought conditions in 1980s and the onset of greener and wetter conditions starting in 1994. These patterns and trends compared well with the new long-term satellite derived rainfall estimates for Africa. We also identified divergence in the trend patterns between the two data sets over the Eastern Sahel, from $\sim 16^{\circ} \mathrm{E}$ to Eastern Sudan that warrant further investigations.

In the context of the past 60 years of rainfall variability over the Sahel Zone since 1951, the NDVI3g time series matched up well with the coincident period of the 50-year VASClimO rainfall for the common period of the two data sets from 1983 to 2000. In particular, NDVI3g quantified the desiccation period from 1982 to1987 in close agreement with the VASClimO rainfall. This illustrates that the NDVI3g can be used as a proxy for Sahelian rainfall at annual time scales. This data set is unique and an important contribution to the study of arid and semi-arid climatic and environmental trends over sub-Saharan Africa and elsewhere since 1981. To ensure the continued availability of this NDVI data set based only on the AVHRR instruments and their unique design, efforts are needed to continue this time series through the operational lifetimes of the MetOp AVHRR instruments to 2020 and possibly beyond.

\section{Acknowledgments}

This work was made possible by funding from USDA Foreign Agricultural Service Global Agricultural Monitoring project through its support of our operational GIMMS NOAA AVHRR NDVI production that is critical input into the NDVI3g long term series data set. We want to extend thanks to three anonymous reviewers whose comments and critical reviews served to improve this manuscript.

\section{Author Contributions}

Assaf Anyamba and Compton Tucker conceived and designed the research, Jennifer Small wrote the analysis software and processed all the data, Edwin Pak processed the input data to NDVI3g, Assaf Anyamba, Jennifer Small, Compton Tucker analyzed and interpreted the data. All authors contributed equally to writing and editing the paper.

\section{Conflicts of Interest}

The authors declare no conflict of interest. 


\section{References}

1. Charney, J. G. Dynamics of deserts and drought in the Sahel. Q.J.R. Meteorol. Soc. 1975, 101, 193-202, doi:10.1002/qj.49710142802.

2. Le Houerou, H.N. The rangelands of the Sahel. J. Range Manag. 1980, 33, 41-46.

3. Le Houerou, H.N. Rain-use efficiency a unifying concept in arid land ecology. J. Arid Environ. 1984, 7, 213-247.

4. Nicholson, S.E. Climatic variations in the Sahel and other African regions during the past five centuries. J. Arid Environ. 1978, 1, 3-24.

5. Nicholson, S.E. Revised rainfall series for the West African subtropics. Mon. Weather Rev. 1979, 107, 473-487.

6. Lamb, P.J. Persistence of Sub-Saharan drought. Nature 1982, 299, 46-48.

7. Folland, C.K.; Palmer, T.N.; Parker, D.E. Sahel rainfall and worldwide sea temperatures, 1901-1985. Nature 1986, 320, 602-607.

8. Tucker, C.J.; Vanpreat, C.L; Sharman, M.J.; van Ittersum, G. Satellite remote sensing of total herbaceous biomass production in the Senegalese Sahel: 1980-1984. Int. J. Remote Sens. 1985, 7, 233-249.

9. Glantz, M.H. Drought, Desertification, and Food Production. In Drought Follows the Plow; Glantz, M.H., Ed.; Cambridge University Press: Cambridge, UK, 1994; pp. 9-30.

10. Zeng, N.; Neelin, J.D.; Lau, K.-M.; Tucker, C.J. Enhancement of interdecadal climate variability in the Sahel by vegetation interaction. Science 1999, 286, 1537-1540.

11. Tucker, C.J. Red and photographic infrared linear combinations for monitoring vegetation. Remote Sens. Environ. 1979, 8, 127-150.

12. Gray, T.I.; Tapley, D.B. Vegetation health: Nature's climate monitor. Adv. Space Res. 1985, 5, 371-377.

13. Tucker, C.J.; Townshend, J.R.G.; Goff, T.E. African lands cover classification using satellite data. Science 1985, 227, 369-375.

14. Nicholson, S.E.; Davenport, M.L.; Malo, A.R. A comparison of vegetation response to rainfall in the Sahel and East Africa using normalized difference vegetation index from NOAA-AVHRR. Clim. Chang. 1990, 17, 209-241.

15. Tucker, C.J.; Newcomb, W.W.; Los, S.O.; Prince, S.D. Mean and inter-annual variation of growing-season normalized difference vegetation index for the Sahel 1981-1989. Int. J. Remote Sens. 1991, 12, 1133-1135.

16. Tucker, C.J.; Dregne, H.; Newcomb, W. Expansion and contraction of the Sahara desert from 1980 to 1990. Science 1991, 253, 299-301.

17. Tucker, C.J.; Nicholson, S.E. Variations in the size of the Sahara Desert from 1980 to 1997. Ambio 1999, 28, 587-591.

18. Rouse, J.W., Jr.; Haas, R.H.; Schell, J.A.; Deering, D.W.; Harlan, J.C. Monitoring the Vernal Advancement and Retrogradation (Green Wave Effect) of Natural Vegetation; NASA/GSFC Type III Final Report; NASA: Greenbelt, MD, USA, 1974.

19. Asrar, G.; Fuchs, M.; Kanemasu, E.T.; Hatfield, J.L. Estimating absorbed photosynthetic radiation and leaf area index from spectral reflectance in wheat. Agron. J. 1984, 76, 300-306. 
20. Sellers, P.J. Canopy reflectance, photosynthesis and transpiration. Int. J. Remote Sens. 1985, 8, 1335-1372.

21. Tucker, C.J.; Newcomb, W.W.; Dregne, H.E. AVHRR data sets for determination of desert spatial extent. Int. J. Remote Sens. 1994, 17, 3547-3565.

22. Anyamba, A.; Tucker, C.J. Analysis of Sahelian vegetation dynamics using NOAA-AVHRR NDVI data from 1981-2003. J. Arid Environ. 2005, 63, 596-614.

23. Herrmann, S.M.; Anyamba, A.; Tucker, C.J. Recent trends in vegetation dynamics in the African Sahel and their relationship to climate. Glob. Environ. Chang. 2005, 15, 394-404.

24. Fensholt, R.; Rasmussen, K.; Nielsen, T.; Mbow, C. Evaluation of earth observation based long term vegetation trends-Intercomparing NDVI time series trend analysis consistency of Sahel from AVHRR GIMMS, Terra MODIS and SPOT VGT data. Remote Sens. Environ. 2009, 113, 1886-1898.

25. Fensholt, R.; Rasmussen, K.; Kaspersen, P.; Huber, S.; Horion, S.; Swinnen, E. Assessing land degradation/recovery in the African Sahel from long-term earth observation based primary productivity and precipitation relationships. Remote Sens. 2013, 5, 664-686.

26. Pinzon, J.E.; Tucker, C.J. A non-stationary 1981-2012 AVHRR NDVI3g time series. Remote Sens. 2014, under review.

27. Love, T.B.; Kumar, V.; Xie, P.; Thiaw, W.M. A 20-Year Daily Africa Precipitation Climatology Using Satellite and Gauge Data. In Proceedings of the 14th Conference on Applied Meteorology, Seattle, WA, USA, 11-15 January 2004.

28. Huete, A.R.; Tucker, C.J. Investigation of soil influences in AVHRR red and near-infrared vegetation index imagery. Int J. Remote Sens. 1991, 12, 1223-1242.

29. Karnieli, A.; Shachak, M.; Tsoar, H.; Zaady, E.; Kaufman, Y.; Danin, A. The effect of microphytes on the spectral reflectance of vegetation in semiarid regions. Remote Sens. Environ. 1996, 2, 88-96.

30. Hiernaux, P.; Mougin, E.; Diarra, L.; Soumaguel, N.; Lavenu, F.; Tracol, Y.; Diawara, M. Sahelian rangeland response to changes in rainfall over two decades in the Gourma region, Mali. J. Hydrol. 2009, 375, 114-127.

31. Nicholson, S.E. Sahel, West Africa. Encycl. Environ. Biol. 1995, 3, 261-275.

32. Nicholson, S.E. The nature of rainfall variability over Africa on time scales of decades to millenia. Glob. Planet. Chang. 2000, 26, 137-158.

33. Lamb, P.J. Sahelian drought. N. Z. J. Geogr. 1980, 68, 12-16.

34. Pinzón, J.; Brown, M.E.; Tucker, C.J. EMD Correction of Orbital Drift Artifacts in Satellite Data Stream. In The Hilbert-Huang Transform and Its Applications; Huang, N., Shen, S., Eds.; World Scientific Publishing: Singapore, 2005; pp. 167-183.

35. Tucker, C.J.; Pinzón, J.E.; Brown, M.E.; Slayback, D.A.; Pak, E.W.; Mahoney, R.; Vermote, E.F.; El Saleous, N. An extended AVHRR 8-km NDVI dataset compatible with MODIS and SPOT Vegetation NDVI data. Int. J. Remote Sens. 2005, 26, 4485-4498.

36. Holben, B.N. Characteristics of maximum-value composite images from temporal AVHRR data. Int. J. Remote Sens. 1986, 7, 1417-1434.

37. Novella, N.S.; Thiaw, W.M. African rainfall climatology version 2 for famine early warning systems. J. Appl. Meteor. Climatol. 2013, 52, 588-606. 
38. Verdin, J.; Funk, C.; Senay, G.; Choularton, R. Climate science and famine early warning. Phiosl. Trans. R. Soc. B 2005, 360, 2155-2168.

39. Beck, C.; Grieser, J.; Rudolf, B. A New Monthly Precipitation Climatology for the Global Land Areas for the Period 1951 to 2000; Klimastatusbericht KSB 2004; DWD: Offenbach, Germany, 2005. Available online: ftp://ftp-anon.dwd.de/pub/data/gpcc/PDF/pdf_28_precipitation.pdf (accessed on 4 April 2014).

40. Rudolf, B.; Schneider, U. Calculation of Gridded Precipitation Data for the Global Land-Surface Using in-situ Gauge Observations. In Proceedings of the 2nd Workshop of the International Precipitation Working Group IPWG, Monterey, CA, USA, 25-28 October 2004; pp. 231-247. Available online: http://www.dwd.de/bvbw/generator/DWDWWW/Content/Oeffentlichkeit/KU/ KU4/KU42/en/Reports_Publications/Calculation,templateId=raw,property=publicationFile.pdf/ Calculation.pdf (accessed on 4 April 2014).

41. Meteorology Department/Florida State University. Nicholson's Africa Precipitation, Monthly 1901-1984; Research Data Archive at the National Center for Atmospheric Research, Computational and Information Systems Laboratory, 1980. Available online: http://rda.ucar.edu/ datasets/ds571.0/ (accessed on 2 April 2014).

42. Fox, J. Linear Models and Least Squares. In Applied Regression Analysis, Linear Models and Related Methods; SAGE Publications, Inc.: Thousand Oaks, CA, USA, 1997; pp. 140-152.

43. Clark, W.A.V.; Hosking, P.L. Statistical Summaries of Distributions. In Statistical Methods for Geographers; John Wiley \& Son: New York, NY, USA, 1986; pp. 90-91.

44. Wilks, D.S. Empirical Distributions and Exploratory Data Analysis. In Statistical Methods in the Atmospheric Sciences; Academic Press, Inc.: San Diego, CA, USA, 1995; pp. 41-44.

45. Helldén, U.; Eklund, L. National Drought Impact Monitoring-A NOAA NDVI and Precipitation Data Study of Ethiopia; Chartwell-Bratt Ltd.: Lund, Sweden, 1988; p. 55.

46. Eklundh, L.; Olsson, L. Vegetation index trends for the African Sahel 1982-1999. Geophy. Res. Lett. 2003, 30, 1430, doi:10.1029/2002GL016772.

47. Helldén, U.; Tottrup, C. Regional desertification: A global synthesis. Glob. Planet. Change 2008, 64, 169-176.

48. Slayback, D.A.; Pinzon, J.E.; Los, S.O.; Tucker, C.J. Northern hemisphere photosynthetic trends 1982-1999. Glob. Change Biol. 2003, 9, 1-15.

49. Nicholson, S.E. Sub-Saharan rainfall 1981-1984. J. Clim. Appl. Meteorol. 1985, 24, 1388-1391.

50. NOAA Climate Prediction Center (NOAA/CPC). Climate Assessment for 1994-Regional Climate Summaries: African Sahel. Available online: http://www.cpc.ncep.noaa.gov/products/ assessments/assess_94/sahel.html (accessed on 29 October 2013).

51. Bell, G.D.; Halpert, M.S.; Schnell, R.C.; Wayne-Higgins, R.; Lawrimore, J.; Kousky, V.E.; Tinker, R.; Thiaw, W.M.; Chelliah, M.; Artusa, A. Climate assessment for 1999. Bull. Am. Meteorl. Soc. 2000, 81, s1-s50.

52. Sánchez-Lugo, A.; Renwick, J.A.; Thiaw, W.M.; Weaver, S.J. Regional climates [In "State of the Climate in 2012"]. Bull. Am. Meteorol. Soc. 2013, 94, S163-S166.

53. Thiaw, W.M.; Cadet, D.L.; Desbois, M. A note on: Estimation of rainfall due to squall lines over West Africa using Meteosat imagery. Meteorol. Atmos. Phys. 1990, 42, 69-76. 
54. Nicholson, S.E.; Grist, J.P. The seasonal evolution of the atmospheric circulation over West Africa and Equatorial Africa. J. Clim. 2003, 16, 1013-1030.

55. Hiernaux, P.; Gerard, B. The influence of vegetation pattern on productivity, diversity and stability of vegetation: The case of "brousse tigree" in the Sahel. Acta Oecol. 1999, 20, 147-158.

56. Webb, P.; Reardon, T. Drought impact and household response in East and West Africa. Q. J. Int. Agric. 1992, 31, 230-246.

57. Nicholson, S.E.; Kim, J. The relationship of the El Nino-Southern Oscillation to African rainfall. Int. J. Clim. 1997, 17, 117-136.

58. Mutai, C.C.; Ward, M.N. East African rainfall and the tropical circulation/convection on intraseasonal to interannual timescales. J. Clim. 2000, 13, 3915-3939.

59. Janicot, S.; Trzaska, S.; Poccard, I. Summer Sahel-ENSO teleconnection and decadal time scale SST variations. Clim. Dynm. 2001, 18, 302-320.

60. Anyamba, A.; Tucker, C.J.; Mahoney, R. From El Niño to La Niña: Vegetation response patterns over East and Southern Africa during the 1997-2000 period. J. Clim. 2002, 15, 3096-3103.

61. Hickler, T.; Eklundh, L.; Seaquist, J. W.; Smith, B.; Ardo, J. ; Olsoon, L.; Sykes, M. T.; Sjostrom, M. Precipitation controls Sahel greening trend. Geo. Res. Lett. 2005, 32, L21415, doi:10.1029/2005GL024370.

62. Warren, A.; Batterbury, S.P.J.; Osbahr, H. Soil erosion in the West African Sahel: A review and an application of a "local political ecology" approach in South West Niger. Glob. Environ. Change 2001, 11, 79-96.

63. Warren, A.; Osbahr, H.; Batterbury, S.P.J.; Chappell, A. Indigenous views of soil erosion at Fandou Béri, southwestern Niger. Geoderma 2003, 111, 439-456.

64. Hulme, M. Climatic perspectives on Sahelian desiccation: 1973-1998. Glob. Environ. Change 2001, 11, 19-29.

(C) 2014 by the authors; licensee MDPI, Basel, Switzerland. This article is an open access article distributed under the terms and conditions of the Creative Commons Attribution license (http://creativecommons.org/licenses/by/3.0/). 